\title{
Compression loading behaviour of sunflower seeds and kernels
}

\author{
Thasaiya A. Selvam ${ }^{1}$, Musuvadi R. Manikantan ${ }^{2 *}$, Tarsem Chand ${ }^{1}$, Rajiv Sharma ${ }^{2}$, \\ and Thirupathi Seerangurayar ${ }^{3}$
}

\begin{abstract}
${ }^{1}$ Department of Processing and Food Engineering, Punjab Agricultural University, Ludhiana-141004, Punjab, India ${ }^{2}$ Food Grains and Oilseeds Processing Division, Central Institute of Post Harvest Engineering and Technology (CIPHET), Ludhiana-141004, Punjab, India

${ }^{3}$ Agricultural Machinery Research Centre, Tamil Nadu Agricultural University, Coimbatore-641003, Tamil Nadu, India
\end{abstract}

Received June 9, 2013; accepted January 6, 2014

\begin{abstract}
A b s t r a c t. The present study was carried out to investigate the compression loading behaviour of five Indian sunflower varieties (NIRMAL-196, NIRMAL-303, CO-2, KBSH-41, and PSH996) under four different moisture levels (6-18\% d.b). The initial cracking force, mean rupture force, and rupture energy were measured as a function of moisture content. The observed results showed that the initial cracking force decreased linearly with an increase in moisture content for all varieties. The mean rupture force also decreased linearly with an increase in moisture content. However, the rupture energy was found to be increasing linearly for seed and kernel with moisture content. NIRMAL-196 and PSH-996 had maximum and minimum values of all the attributes studied for both seed and kernel, respectively. The values of all the studied attributes were higher for seed than kernel of all the varieties at all moisture levels. There was a significant effect of moisture and variety on compression loading behaviour.

$\mathrm{K}$ e y w o r d s: sunflower seed, compression loading, rupture energy, moisture content
\end{abstract}

\section{INTRODUCTION}

Sunflower (Helianthus annuus L) is one of the major oilseed crops used for oil production (90\%) and fresh consumption (10\%). The oil extracted from sunflower seeds is a good source of vegetable oil for cooking and manufacturing of margarine, paints, soaps, and cosmetics (Bamgboye and Adejumo, 2007). Its use as biodiesel, or as vegetableoil based fuel for many vehicles, including farming equipment is feasible (Antolin et al., 2002). In India, oil is mostly obtained by mechanical expression from sunflower seeds. However, this process suffers from certain drawbacks. The presence of a high percentage of hull in the seed (varies between 20 and $30 \%$ depending on the variety and is main- ly full of crude fiber and unimportant quantity of fat) not only causes rapid wear of the moving parts of the expeller but also reduces the total oil yield, transfers pigments from the hull to the extracted oils, and yields cakes of lower food value (Khodabakhshian et al., 2010). In order to design an efficient dehulling system and equipment for mechanical expression of oil and other processes, fracture characteristics of sunflower seed and kernel are essential at different moisture levels under compressive loading.

Many researchers have studied the mechanical properties of various agricultural materials such as corn seed (Babic et al., 2013), soybean (Bargale et al., 1999), white sesame seed (Darvishi, 2012), and maize (Barnwal et al., 2012). Joshi (1993) observed that the force required to initiate seed coat rupture of pumpkin seed increased as moisture content increased from 5.1 to $10.5 \%$ d.b., beyond which it steadily decreased up to a moisture content of $21.7 \%$ d.b. It was also reported that deformation occurring at seed coat or kernel rupture increased as seed moisture content increased from 5.1 to $21.7 \%$ d.b. and it was substantially greater for the seed loaded in the vertical orientation than the horizontal one. Energy absorbed by the seed and kernel increased in both horizontal and vertical orientations of loading as the moisture content increased to $15 \%$ d.b. Beyond this moisture content, the energy absorbed declined. Kang et al. (1995) reported that mean values of bio-yield strain and energy to bio-yield of wheat decreased as the moisture content increased at a loading rate of 1 to $250 \mathrm{~mm} \mathrm{~min}^{-1}$. Owolarafe et al. (2005) studied the average cracking force, and average pressure required for cracking of fresh palm 
fruit are $2301 \mathrm{~N}$ and $5.79 \mathrm{~N} \mathrm{~mm}^{-2}$, respectively. Baumler et al. (2006) studied the compression behaviour of safflower seed under quasi-static compressive loading at six levels of moisture content varying from 3.7 to $15.6 \%$ d.b. The samples were tested in horizontal and vertical orientations. It was observed that the force required for hull rupture decreased as the moisture content increased, and it attained a minimum value at $11 \%$ d.b. The energy absorbed at rupture per unit volume of seeds for the horizontal position was always higher than that for the vertical one.

Sunflower oil is mostly obtained by mechanical expression from sunflower seeds, the process mainly consists of flaking and crushing which is related to the external forces on each seed between the crushing surfaces. Considering a varietal effect dependency on moisture content, no detailed published literature was found according to authors best of knowledge. However, Gupta and Das (2000) studied fracture resistance characteristics of the Morden sunflower variety with two different orientations. It was found that rupture force decreased from 59.12 to $35.26 \mathrm{~N}$ for seed and from 13.59 to $8.50 \mathrm{~N}$ for the kernel, respectively. The deformation and energy absorbed at rupture increased for both seed and kernel under horizontal and vertical orientations. Khodabakhshian et al. (2010) investigated mechanical properties of Iranian sunflower seed under quasistatic loading. It was observed that rupture force for both seed and kernel decreased with increasing moisture content from 3 to $14 \%$ even as the absorbed energy and deformation at rupture increased for all sizes (small, medium and large) in both horizontal and vertical loading orientations.

Thus keeping in view, the major objective of this study was to investigate the compression loading behaviour of five widely cultivated Indian sunflower hybrids at different moisture content. The initial cracking force, mean rupture force, and rupture energy of the sunflower seeds as well as kernels under compression loading were examined over a range of moisture content 6-18\% d.b.

\section{MATERIALS AND METHODS}

Five varieties of widely cultivated Indian sunflower hybrids having high seed yield, high oil content, low hull content and tolerance to diseases, namely PSH-996, NIRMAL-196, NIRMAL-303, KBSH-41, and CO-2 were obtained from different regions in India during July 2012. The seeds were cleaned and graded using an appropriate set of sieves in a cleaner and grader developed by the Central Institute of Agricultural Engineering (CIAE, India) to remove foreign matter as well as broken and immature seed. To obtain whole kernel, the seeds were dehulled using an impact-type sunflower dehuller (CIPHET, India). The mean initial moisture content of the seed and kernel was determined by the standard hot air oven method with the temperature settings of $130 \pm 1^{\circ} \mathrm{C}$ for three hours (ASAE, 1999). The initial average moisture content of the whole seed as well as kernel varied from 5.6 to 7.3 and 4.8 to $6.7 \%$ d.b., respectively. The experimental moisture of the samples $(6,10,14$ and $18 \%$ d.b.) was chosen according to the prevailing processing practices and obtained with either adding or removing water using the expression followed by Khodabakhshain et al. (2010).

The conditioned samples were sealed in low density polyethylene bags of $90 \mu \mathrm{m}$ thickness and kept in a refri gerator at $4^{\circ} \mathrm{C}$ for one week for uniform distribution of moisture throughout the sample. Before starting the experiment, a required quantity of the sample was taken out from the refrigerator and allowed to equilibrate with room temperature for two hours (Singh and Goswami, 1996).

Compression loading tests such as initial cracking force, mean rupture force and rupture energy were performed with a Texture Analyzer (TA-HDi., Stable micro systems). The conditioned samples were visually inspected and randomly selected prior to testing, and those with visible immature seeds were discarded. Each individual seed or kernel was kept in natural rest position under the test probe and it was compressed at the pre-set condition until rupture occurred as is denoted by a bio-yield point (Sukumaran and Singh, 1989). The condition-set up in the texture analyzer for measuring compression test were: pre-test speed -1.0 ; test speed -2 ; post-test speed $-5 \mathrm{~mm} \mathrm{~s}^{-1}$; test distance $-5 \mathrm{~mm}$; trigger type - auto; trigger force $-0.10 \mathrm{~N}$; load cell $-50 \mathrm{~kg}$; stainless steel cylinder probe $-5 \mathrm{~mm}$ diameter. A graph was drawn between the force resisted by the test material and time. From the graph, the initial peak position was considered as initial cracking of the test material and the force related to this initial peak position was considered as initial cracking force. The mean force experienced by the test material from zero to the test distance is considered as mean rupture force and the area under this curve is known as rupture energy.

The experiments were conducted with three replications for each moisture level and variety, and the mean values are reported. The effect of variety and moisture content on compression loading behaviour of both sunflower seeds and kernels was investigated using analysis of variance (ANOVA) at $5 \%$ significance with the help of SPSS 20.0 software.

\section{RESULTS AND DISCUSSION}

The variation of initial cracking force of sunflower seed and kernel with standard error at 5\% significance at different moisture contents are given in Fig. 1a,b, respectively. The force required to initiate rupture of sunflower seed as well as kernel for each variety decreased as the moisture content increased from 6 to $18 \%$ d.b. The mean initial cracking force of NIRMAL-196, NIRMAL-303, CO-2, KBSH-41, and PSH-996 sunflower seed ranged from $75.05-59.14,58.88-52.48,52.15-48.93,47.08-41.88$, and $36.50-28.88 \mathrm{~N}$, respectively. The values for kernels varied 

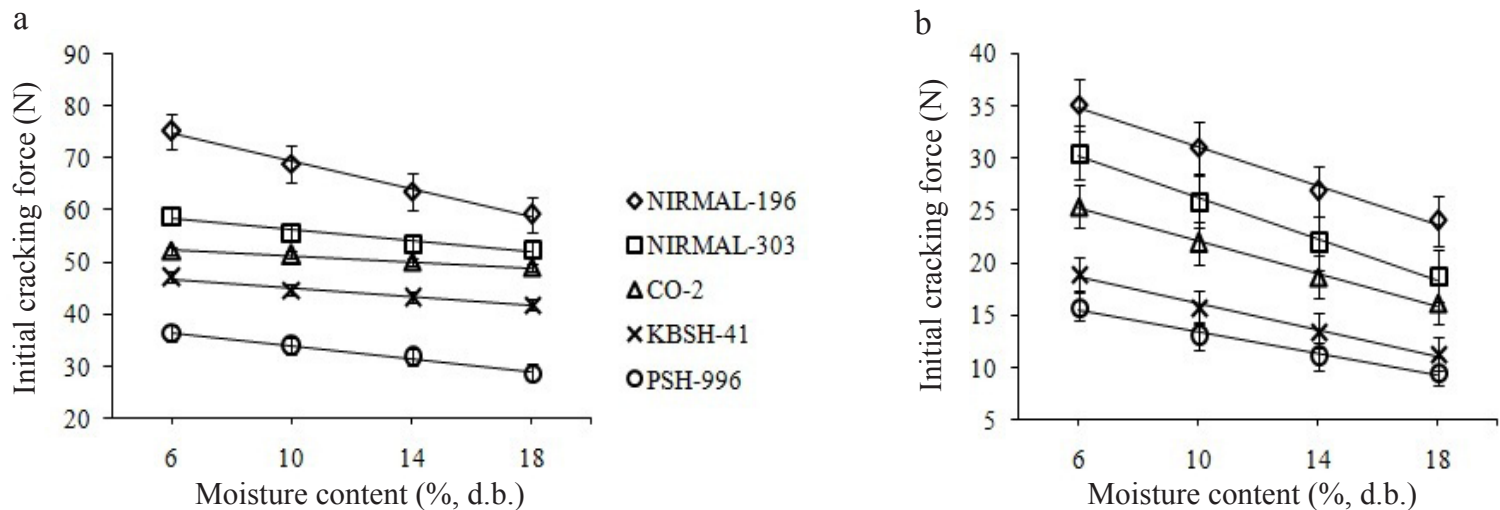

Fig. 1. Effect of moisture content on initial cracking force of sunflower: $a-$ seed, $b$ - kernel.

from 35.06-24.04, 30.54-18.77, 25.40-16.11, 18.91-11.28, and $15.77-9.57 \mathrm{~N}$, respectively. This may be due to the fact that at higher moisture content, the seed became softer and required less force (Saiedirad et al., 2008). Among all the studied varieties, the maximum force required to initiate the crack was exhibited by NIRMAL-196 for both seed and kernel followed by NIRMAL-303, CO-2, KBSH-41, and PSH-996. The trend of decreasing initial cracking force at higher moisture content might also be due to a gradual change in the integrity of the cellular matrix (Khodabakhshain et al., 2010). Similar trends were also observed by Khodabakhshian and Shakeri (2012) for safflower, Gupta and Das (2000) for the 'Morden' variety of sunflower, and Darvishi (2012) for white sesame seed. The effect of moisture and variety on initial cracking force for sunflower seed and kernel was also studied using ANOVA and it is shown in Table 1. The moisture content and variety significantly influenced the initial cracking force $(p<0.05)$ for both seed and kernel. The interaction of moisture content and variety was also found to have a significant effect on initial cracking force. The regression equations and their respective coefficients of determination $\left(\mathrm{R}^{2}\right)$ for the measured initial cracking force of seed and kernel as a function of moisture content are presented in Table 2. As the coefficient of determination $\left(\mathrm{R}^{2}\right)$ was adequately high, it seems that the moisture content had a remarkable influence on the measured parameters.

The mean rupture force of sunflower seed and kernel of the different varieties with standard error at $5 \%$ significance at different moisture contents are presented in Fig. 2a, b, respectively. For all the varieties, the mean rupture force decreased linearly with the increase in moisture content. The mean rupture force of NIRMAL-196, NIRMAL-303, CO-2, KBSH-41, and PSH-996 sunflower seed ranged from 138.54-110.15, 109.48-89.49, 106.91-85.86, 98.13- 76.46, and 82.88-67.92 N, respectively. Similarly, the mean rupture force for kernel decreased from 72.95-58.90, 66.22-44.21, 60.19-37.88, 56.85-29.28, and 54.06-19.44 N, respectively. The experimental results showed that NIRMAL-196 and
PSH-996 had maximum and minimum values of mean rupture force for both seed kernel respectively. While comparing the values of mean rupture force, the values for seed were always found higher than those for kernel. A similar trend was observed by Bargale et al. (1995) for canola and wheat. Table 1 summarized the analysis of variance which was carried out to investigate the effect of moisture content and variety on mean rupture force for sunflower seed as well as kernel. From the tables, it was observed that the changes in variety and moisture content influenced significantly the mean rupture force of seed and kernel $(p<0.05)$. Regression equations and their coefficients of determination $\left(\mathrm{R}^{2}\right)$ obtained for the mean rupture force of sunflower seed and kernel are presented as a function of variety and moisture content in Table 2. These equations and coefficients confirm a linear behaviour for all the varieties.

The variations of rupture energy as a function of moisture content and variety for sunflower seed and kernel with standard error at 5\% significance are shown in Fig. 3a, b, respectively. The rupture energy for all five varieties of sunflower seed and kernel increased linearly with moisture content. Theruptureenergy of NIRMAL-196, NIRMAL-303, CO-2, KBSH-41, and PSH-996 sunflower seed increased from 27.98-56.59, 25.40-52.94, 23.60 -48.76, 19.15-46.22, and 16.97-43.37 $\mathrm{N} \mathrm{mm}$, respectively. In turn, the values for kernel varied from 17.16-27.73, 14.71-24.65, 12.97-22.01, 9.79-18.44, and 6.18-11.95 N mm, respectively. Among all the studied varieties, the least rupture energy for both seed and kernel was obtained for PSH-996, with 16.97 and $6.18 \mathrm{~N} \mathrm{~mm}$, respectively. On the other hand, NIRMAL-196 had the highest rupture energy for both seed and kernel, with 56.59 and $27.73 \mathrm{~N} \mathrm{~mm}$, respectively. Similar to the mean rupture force, the rupture energy was also observed higher in the case of seed as compared to kernel at each level of moisture content. The increasing trend may be due to the fact that rupture energy is a function of both force and deformation up to bio-yield point (Mohsenin, 1986). At low moisture content, the seed requires high force to be ruptured and its deformation was low but at high moisture content, 
T a b l e 1. ANOVA to study the effect of variety and moisture content on compression loading behaviour of sunflower seed and kernel

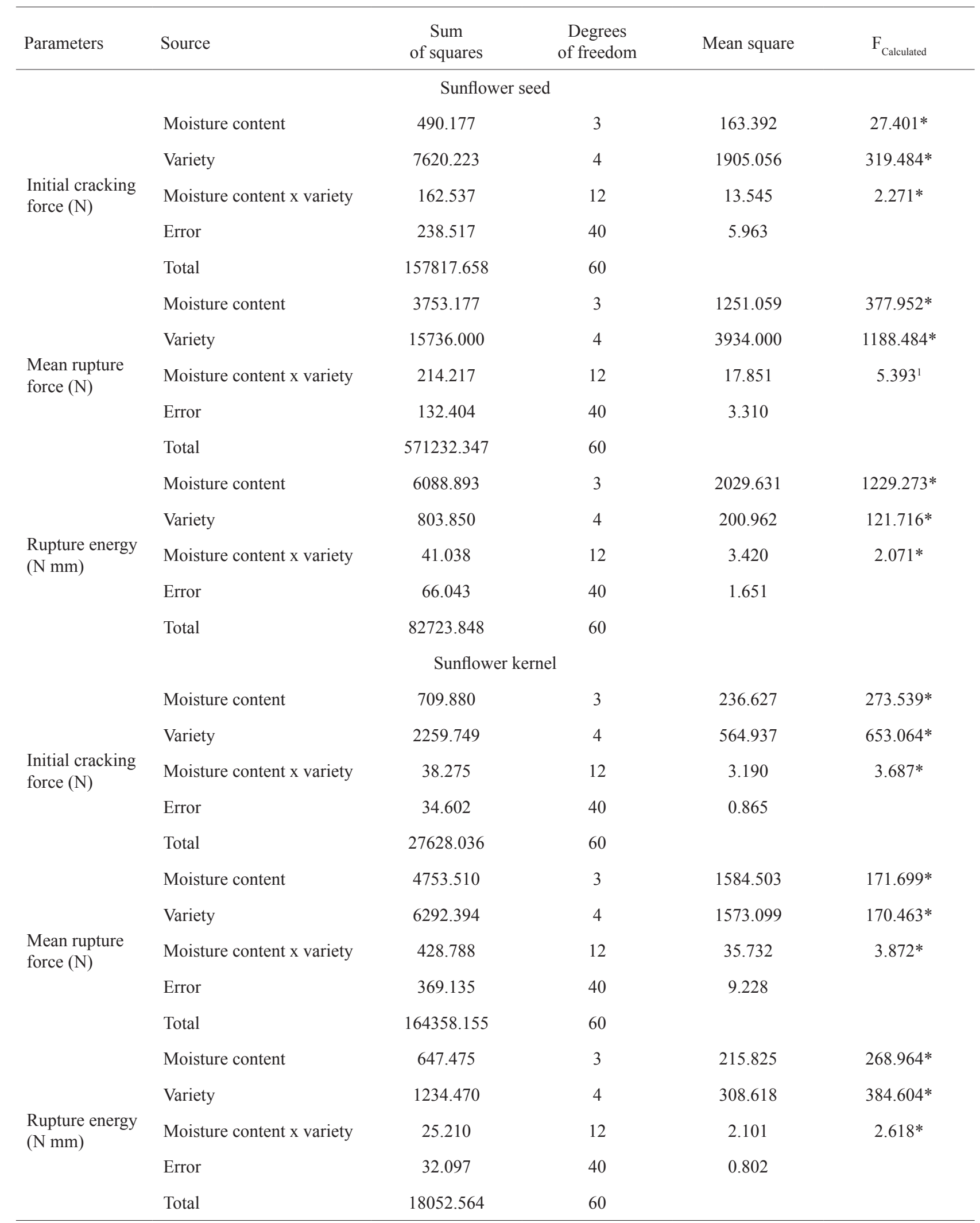

Moisture content $\mathrm{x}$ variety - interaction of moisture content and variety. $*$ Significant at $\mathrm{p} \leq 0.05$. 
T a b l e 2. Regression equations and coefficient of determination $\left(\mathrm{R}^{2}\right)$ for compression loading behaviour of sunflower seed and kernel as a function of moisture content (M, \% d.b.)

\begin{tabular}{|c|c|c|c|c|c|}
\hline \multirow{2}{*}{ Parameters } & \multirow{2}{*}{ Variety } & \multicolumn{2}{|c|}{ Sunflower seed } & \multicolumn{2}{|c|}{ Sunflower kernel } \\
\hline & & Regression equation & $\mathrm{R}^{2}$ & Regression equation & $\mathrm{R}^{2}$ \\
\hline \multirow{5}{*}{$\begin{array}{l}\text { Initial cracking } \\
\text { force }(\mathrm{N})\end{array}$} & NIRMAL-196 & $-5.304 \mathrm{M}+79.91$ & 0.994 & $-3.719 \mathrm{M}+38.53$ & 0.993 \\
\hline & NIRMAL-303 & $-2.134 \mathrm{M}+60.52$ & 0.959 & $-3.926 \mathrm{M}+34.06$ & 0.991 \\
\hline & $\mathrm{CO}-2$ & $-1.098 \mathrm{M}+53.34$ & 0.993 & $-3.114 \mathrm{M}+28.29$ & 0.994 \\
\hline & KBSH-41 & $-1.707 \mathrm{M}+48.47$ & 0.978 & $-2.512 \mathrm{M}+21.14$ & 0.991 \\
\hline & PSH-996 & $-2.501 \mathrm{M}+39.02$ & 0.997 & $-2.051 \mathrm{M}+17.48$ & 0.981 \\
\hline \multirow{5}{*}{$\begin{array}{l}\text { Mean rupture } \\
\text { force }(\mathrm{N})\end{array}$} & NIRMAL-196 & $-9.664 \mathrm{M}+147.9$ & 0.993 & $-4.443 \mathrm{M}+77.68$ & 0.958 \\
\hline & NIRMAL-303 & $-6.577 \mathrm{M}+115.1$ & 0.986 & $-7.188 \mathrm{M}+74.22$ & 0.979 \\
\hline & $\mathrm{CO}-2$ & $-6.919 M+111.9$ & 0.948 & $-7.375 \mathrm{M}+67.26$ & 0.998 \\
\hline & KBSH-41 & $-7.014 \mathrm{M}+105.3$ & 0.987 & $-9.232 \mathrm{M}+66.32$ & 0.999 \\
\hline & PSH-996 & $-5.045 \mathrm{M}+87.04$ & 0.970 & $-11.5 \mathrm{M}+65.930$ & 0.998 \\
\hline \multirow{5}{*}{$\begin{array}{l}\text { Rupture energy } \\
\text { (N mm) }\end{array}$} & NIRMAL-196 & $9.451 \mathrm{M}+17.08$ & 0.977 & $3.488 \mathrm{M}+13.56$ & 0.997 \\
\hline & NIRMAL-303 & $9.138 \mathrm{M}+15.15$ & 0.986 & $3.335 \mathrm{M}+10.88$ & 0.984 \\
\hline & $\mathrm{CO}-2$ & $8.446 \mathrm{M}+14.74$ & 0.998 & $3.061 \mathrm{M}+9.679$ & 0.995 \\
\hline & KBSH-41 & $9.086 \mathrm{M}+9.771$ & 0.999 & $2.880 \mathrm{M}+6.818$ & 0.999 \\
\hline & PSH-996 & $8.855 \mathrm{M}+8.427$ & 0.998 & $1.904 \mathrm{M}+4.310$ & 0.999 \\
\hline
\end{tabular}

a

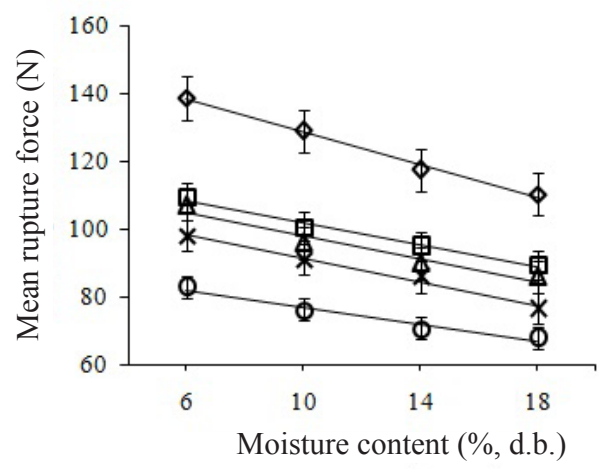

b

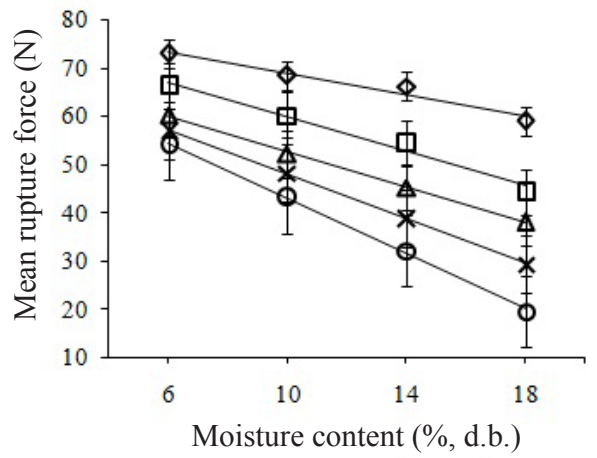

Fig. 2. Effect of moisture content on mean rupture force of sunflower: a - seed, b - kernel. Legends as in Fig. 1.

the rupture force was low and the deformation was high (Khodabakhshain et al., 2010). The increasing trend of rupture energy with an increase in moisture content was also documented for some other seeds, such as safflower and white sesame seed by Khodabakhshian and Shakeri (2012), and Darvishi (2012), respectively. The results of statistical analysis indicated that moisture content and variety had a significant effect on rupture energy for both seed and kernel at $\mathrm{p}<0.05$ (Table 1). Similarly, the interaction of moisture content and variety also had a significant effect on rupture energy $(p<0.05)$ for both seed and kernel. The regression equations and their respective coefficients of determination $\left(\mathrm{R}^{2}\right)$ for the measured rupture energy of seed and kernel as a function of moisture content are presented in Table 2. 


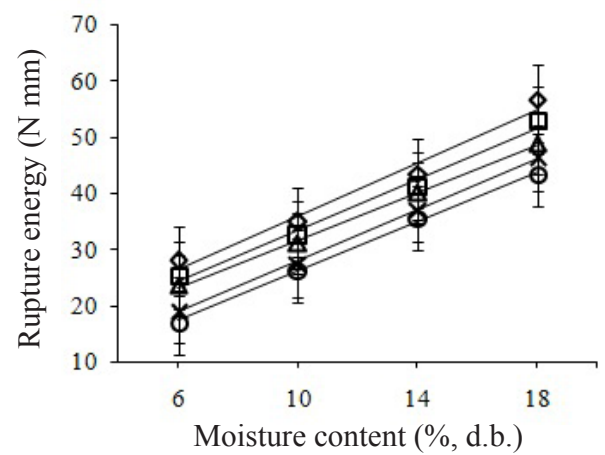

b

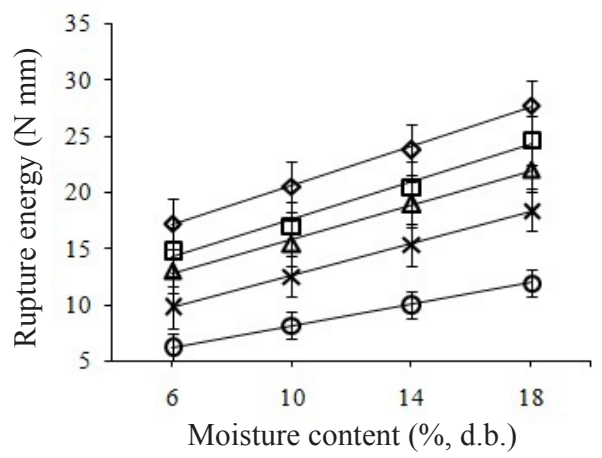

Fig. 3. Effect of moisture content on rupture energy of sunflower: $a$ - seed, b - kernel. Legends as in Fig. 1.

\section{CONCLUSIONS}

1. Initial cracking force of sunflower seed and kernel decreased with an increase in moisture content for all the studied varieties, NIRMAL-196 had a maximum initial cracking force for both seed and kernel.

2 . The mean rupture force also linearly decreased with an increase in moisture content from 6-18\% d.b. Among all the varieties studied, NIRMAL-196 and PSH-996 had maximum and minimum values for both seed and kernel, respectively.

3. The rupture energy for both seed and kernel increased linearly with moisture content. Moreover, rupture energy of kernel was lower than that of seed for all the varieties in the whole range of moisture content.

4. Among the studied varieties, NIRMAL-196 had the highest rupture energy for both seed and kernel, with 56.59 and $27.73 \mathrm{~N} \mathrm{~mm}$, respectively.

5. Changes in moisture content and varieties of five Indian sunflower seed and kernel exerted a significant effect on its compression loading behaviour. This study will be helpful to determine the force and energy required for dehulling and oil expression.

\section{REFERENCES}

Antolin G., Tinaut F.V., Briceno Y., Castano V., Perez C., and Ramirez A.I., 2002. Optimisation of biodiesel production by sunflower oil transesterification. Bioresource Technol., 83, 111-114.

ASAE, 1999. ASAE Standards S352.2. Moisture measurementunground grain and seeds. ASAE, St. Joseph, MI, USA.

Babic L.J., Radojcin M., Pavkov I., Babic M., Turan J., Zoranovic M., and Stanisic S., 2013. Physical properties and compression loading behavior of corn seed. Int. Agrophys., 27, 119-126.

Bamgboye A. and Adejumo A., 2007. Development of a sunflower oil expeller. Agric. Eng. Int., 9, 1-7.
Bargale P.C., Ford R.J., Sosulski F.W., Wulfsohn D., and Irudayaraj J., 1999. Mechanical oil expression from extruded soybean samples. JAOCS, 76(2), 223-229.

Bargale P.C., Irudayaraj J., and Marquis B., 1995. Studies on rheological behavior of canola and wheat. J. Agric. Eng. Res., 61, 267-274.

Barnwal P., Kadam D.M., and Singh K.K., 2012. Influence of moisture content on physical properties of maize. Int. Agrophys., 26, 331-334.

Baumler E., Cuniberti A., Nolasco S.M., and Riccobene I.C., 2006. Moisture dependent physical and compression properties of safflower seed. J. Food Eng., 72, 134-140.

Darvishi H., 2012. Moisture-dependent physical and mechanical properties of white sesame seed. Am-Euras. J. Agric. Environ. Sci., 12(2), 198-203.

Gupta R.K. and Das S.K., 2000. Fracture resistance of sunflower seed and kernel to compressive loading. J. Food Eng., 46, 1-8.

Joshi D.C., 1993. Mechanical dehulling of pumpkin seed. Ph.D. Thesis, Agric. Engineering Department, Kharagpur, India.

Kang Y.S., Spillman C.K., Steele J.L., and Chung D.S., 1995. Mechanical properties of wheat. Trans. ASAE, 38(2), 573-578.

Khodabakhshian R., Emadi B., Fard M.H.A., and Saiedirad M.H., 2010. Mechanical properties of sunflower seed and its kernel, azargol variety as a case study, under compressive loading. J. Agric. Sci. Technol., 4 (2), 34-40.

Khodabakhshian R. and Shakeri M., 2012. Investigation on some mechanical aspects of safflower seed to the design of processing equipment. J. Agric. Technol., 8(1), 39-48.

Mohsenin N.N., 1986. Physical properties of plant and animal materials. Gordon Breach Sci. Press, New York, USA.

Owolarafe O.K., Olabige M.T., and Faborode M.O., 2007. Physical and mechanical properties of two varieties of fresh oil palm fruit. J. Food Eng., 78, 1228-1232.

Saiedirad M.H., Tabatabaeefar A., and Borghei M., 2008. Effect of moisture content, seed size, loading rate and seed orientation on force and energy required for fracturing cumin seed under quasi-static loading. J. Food Eng., 86, 565-572.

Singh K.K., and Goswami T.K., 1996. Physical properties of cumin Seed. J. Agric. Eng. Res., 64, 93-98.

Sukumaran C.R. and Singh B.P.N., 1989. Compression of a bed of rapeseeds: The oil point. J. Agric. Eng. Res., 42, 77-84. 